\section{OPEN ACCESS}

Edited by:

Evgeny V. Mishin

Air Force Research Laboratory,

United States

Reviewed by:

Ivan A. Galkin,

University of Massachusetts Lowell,

United States

Alexei V. Dmitriev,

Lomonosov Moscow State University,

Russia

*Correspondence:

Gennady Milkh

milikh@gmail.com

Specialty section:

This article was submitted to

Space Physics,

a section of the journal

Frontiers in Astronomy and Space

Sciences

Received: 30 November 2018

Accepted: 27 February 2019

Published: 22 March 2019

Citation:

Yampolski Y, Milikh G, Zalizovski A, Koloskov A, Reznichenko A, Nossa E, Bernhardt PA, Briczinski S, Grach SM

Shindin A and Sergeev E (2019)

lonospheric Non-linear Effects Observed During Very-Long-Distance HF Propagation.

Front. Astron. Space Sci. 6:12. doi: 10.3389/fspas.2019.00012

\title{
lonospheric Non-linear Effects Observed During Very-Long-Distance HF Propagation
}

\author{
Yuri Yampolski ${ }^{1}$, Gennady Milikh ${ }^{2 *}$, Andriy Zalizovski ${ }^{1}$, Alexander Koloskov ${ }^{1,3}$, \\ Artem Reznichenko ${ }^{1}$, Eliana Nossa ${ }^{4,5}$, Paul A. Bernhardt ${ }^{4}$, Stan Briczinski ${ }^{4}$, \\ Savely M. Grach ${ }^{6}$, Alexey Shindin ${ }^{6}$ and Evgeny Sergeev ${ }^{6}$
}

${ }^{1}$ Institute of Radio Astronomy of National Academy of Sciences of Ukraine, Kharkov, Ukraine, ${ }^{2}$ Department of Astronomy, University of Maryland, College Park, MD, United States, ${ }^{3}$ National Antarctic Scientific Center of Ukraine, Kyiv, Ukraine, ${ }^{4}$ Naval Research Laboratory, Washington, DC, United States, ${ }^{5}$ Arecibo Observatory, Arecibo, PR, United States,

${ }^{6}$ Department of Radiophysics, Lobachevsky State University of Nizhny Novgorod, Nizhny Novgorod, Russia

A new super-long-range wave propagation technique was implemented at different High Frequency (HF) heating facilities. The HF waves radiated by a powerful heater were scattered into the ionospheric waveguide by the stimulated field aligned striations. This waveguide was formed in a valley region between the E- and F- layers of the ionosphere. The wave trapping and channeling provide super-long-range propagation of HF heater signals detected at the Ukrainian Antarctic Academik Vernadsky Station (UAS) which is many thousand kilometers away from the corresponding HF heating facility. This paper aims to study the excitation of the ionospheric waveguide due to the scattering of the HF heating wave by artificial field aligned irregularities. In addition, the probing of stimulated ionospheric irregularities can be obtained from analyses of the signals received at far distance from the HF heater. The paper uses a novel method of scattering of the HF radiation by the heating facility for diagnostics of non-linear effects at the super-long radio paths. Experiments were conducted at three different powerful HF facilities: EISCAT (Norway), HAARP (Alaska), and Arecibo (Puerto Rico) and by using different far spaced receiving sites. The key problems for super-long-range propagation regime is the feeding of ionospheric waveguide. Then the energy needs to exit from the waveguide at a specific location to be detected by the surface-based receiver. During our studies the waveguide feeding was provided by the scattering of HF waves by the artificial ionospheric turbulence (AIT) above the HF heater. An interesting opportunity for the channeling of the HF signals occurs due to the aspect scattering of radio waves by field aligned irregularities (FAl), when the scattering vector is parallel to the Earth surface. Such FAls geometry takes place over the Arecibo facility. Here FAl are oriented along the geomagnetic field line inclined by 43 degrees. Since the Arecibo HF beam is vertical, the aspect scattered waves will be oriented almost horizontally toward the South. Such geometry provides unique opportunity to channel the radio wave energy into the ionospheric waveguide and excites the whispering gallery modes.

Keywords: artificial ionospheric turbulence, very-long-distance propagation, whisper gallery, ionospheric waveguide, self-scattering 


\section{INTRODUCTION}

Under the influence of powerful radio emissions on the ionospheric plasma, a variety of non-linear effects occur (Gurevich, 2007). These include electron heating, striction, and thermal parametric instability, stimulated electromagnetic emission, radial drifts in the heated region, and so on. The non-linear interference of the powerful radio wave with the ionosphere produces plasma disturbances and creates the broad spectrum of the inhomogeneities, known as artificial ionospheric turbulence (AIT). The AIT generated by HF heating was first reported by Thorne and Blood (1974) who used the Platteville facility located near Boulder, Colorado, USA. Later studies of AIT were conducted in the next generation of heating facilities such as the European Incoherent Scatter (EISCAT), the High Frequency Active Auroral Research Program (HAARP), Arecibo, and Russian facility Sura. Early diagnostic tools to probe AIT included RF, VHF, and UHF coherent radars and optical detectors. Later they were joined by incoherent UHF incoherent radars at EISCAT and Arecibo, as well as by GPS and LEO satellites, such as French satellite Demeter. Yampolski et al. (1997) conducted experiment at the Sura facility using HF broadcasting station as a probing wave while the UTR-2 Radio telescope (Kharkov, Ukraine) was used as a receiver. In a similar experiment, Ponomarenko et al. (1999) used the heating HF frequency close to multiple electron gyroresonance and found that the spectrum of scattered probe wave experienced strong broadening. It was related to the excitation of small plasma striations. Moreover, stimulated electromagnetic emission (SEE) was successfully used to diagnose AIT (Leyser et al., 1989, 1993, 1994; Carozzi et al., 2002; Thide et al., 2005; Norin et al., 2008, 2009; Bernhardt et al., 2009, 2011; Sergeev et al., 2013; Grach et al., 2016).

AIT leads to the resonance scattering of HF-VHF waves by the irregularities with the scales comparable to the wavelength. In addition, the waves will be focused (or defocused) at scales of the Fresnel zone. Different AIT diagnostics are based on these effects. They include coherent and incoherent radars, vertical ionospheric sounding, and ionospheric radioscopy scintillation technique.

The HF waves radiated by a powerful heater were scattered into the ionospheric waveguide. This waveguide is formed in a valley region between the electron density peaks of the E- and Flayers (Davies, 1989). The waveguide is located at high altitude where the electron collision frequency drops and thus the wave attenuation becomes very low. That allows the radio waves to propagate to long distances. In fact, the waves emitted at HAARP were observed at the Ukrainian Antarctic Academik Vernadsky Station (UAS) with coordinates $65.25 \mathrm{~S}, 64.25 \mathrm{~W}$, located many thousand kilometers away from the heating facility.

The key problem of providing the waveguide propagation regime is the feeding of the ionospheric waveguide, which is located in the valley between the $\mathrm{E}$ and $\mathrm{F}$ ionospheric regions. Then the energy needs to exit from the waveguide at a specific location to be detected by the surface-based receiver. During our studies the waveguide feeding was provided by scattering of the HF waves off the AIT above the HF heater. In the indicatrices of the resonance signal scattering by AIT a fraction of energy propagates within the sliding angle along the waveguide axes thus providing its feeding.

It is known that effective conditions for the waveguide excitation, as well as signal landing from the waveguide, are created by the regular horizontal gradients which appear during sunset and sunrise in the ionosphere. Such conditions were forecasted for HF heating campaigns by EISCAT and HAARP both located in the North Chemosphere while the receiving UAS site was in Antarctica. Figure 1 shows the map with the radiopaths EISCAT-UAS, HAARP-UAS, SURA-UAS, and AreciboUAS marks the dates when the solar terminator passes through those radio-paths (since the radio link Arecibo-UAS is practically meridional the terminator passes across it during equinoxes). Since HF heating campaigns are irregular, the UAS is monitoring continuously the propagation conditions for HF signals. Since 2002, the systematic monitoring of the probe signals radiated by the two HF time service stations CHU (Ottawa, Canada) and RWM (Moscow, Russia) was conducted. Such observations are useful for the comparable analysis of behavior of signals emitted by the HF heating facilities and for the identification of mechanisms related to the waveguide feeding.

An even more interesting opportunity for channeling of the HF signals occurs due to the aspect scattering of radio waves by the field aligned plasma irregularities (FAI), when the scattering vector is parallel to the Earth surface. Such FAIs geometry takes place over the Arecibo HF facility. Here FAIs are oriented along the geomagnetic field line inclined at about $43^{\circ}$. Since the Arecibo HF beam is vertical, the aspect scattered wave will be oriented almost horizontally toward the South. Such geometry provides unique opportunity to channel the radio wave energy into the ionospheric waveguide and excites the whispering gallery modes (Budden and Martin, 1962; Erukhinov et al., 1975). The whispering gallery modes require only the ionospheric $\mathrm{F}$ region curvature, and it does not depend on the E region existence. Those conditions can be fulfilled during the nighttime. If the wave emission can be produced parallel to the Earth surface at the ionospheric altitudes, it can provide the energy to enter and exit from the wave channel. We will show later on in this paper that by choosing the proper conditions of the aspect scattering of the HF signals by FAIs, one can execute such opportunity.

\section{Objectives}

This paper is aimed to study the excitation of the ionospheric waveguide due to scattering of the HF heating wave by the artificial ionospheric turbulence (AIT).

\section{Methodology}

All three experiments used similar methodology. As a probe wave we used the emission of the powerful HF heater scattered off the AIT. The radiation was observed using coherent HF receivers at very long distance $(\geq 9,000 \mathrm{~km})$ from the powerful transmitter. In those experiments the heating signals are caused by the resonance scattering of the emission off the decameter scale irregularities being of the order of wavelength of the incident wave. The control of the scattering characteristics is provided by the suitable choice of the heating regime and the Sun illumination of the 


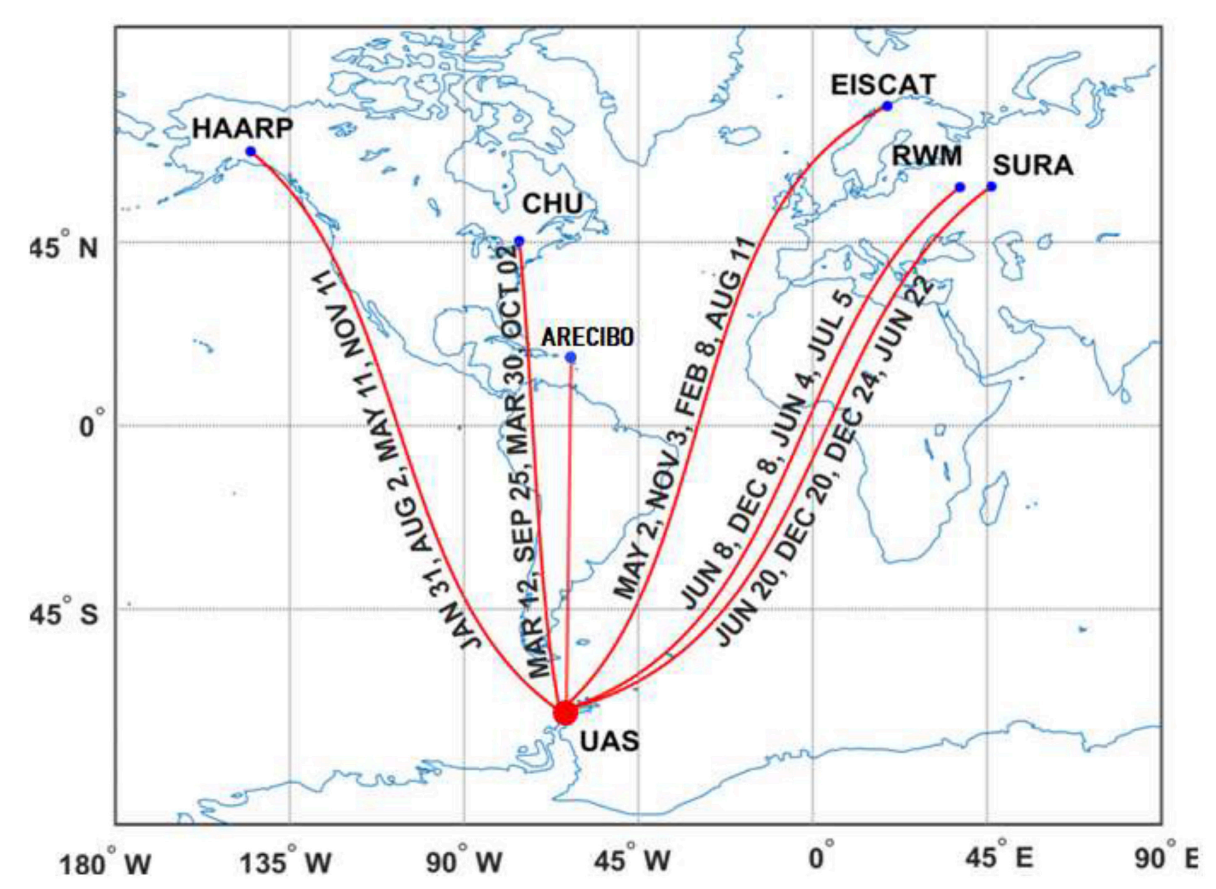

FIGURE 1 | Map of the solar terminator lines and super-long range radio paths.

ionosphere. This way, the ionospheric waveguide can be fed at the beginning of the transmitting line. The energy extraction from the ionospheric wave guide is provided either by refraction off the natural horizontal gradients of the electron concentration (for example during sunset and sunrise) or by scattering off the natural irregularities near the receiver's location. The most convenient conditions for this process occur when the E-layer that screens the energy extraction from the waveguide is absent, i.e., at dusk. Nevertheless, most of the radio link should be Sun illuminated while the E-layer which serves as a lower boundary of the wave guide exists. Consider that the receiver is located in the Antarctic, which is a high latitude region and as such acquires high levels of natural turbulence, it is likely to find here natural irregularities of the decameter scale even during quiet ionospheric conditions.

Experiments were conducted at three different powerful $\mathrm{HF}$ facilities: EISCAT, HAARP, and Arecibo and by using different far spaced receiving sites. Note that all discussed results were obtained under quiet geophysical conditions (quiet ionosphere and unperturbed magnetic field). The results of the heating campaigns will be discussed in the chronological order in which they were performed.

\section{SELF-SCATTERING EFFECT DETECTED AT EISCAT}

The first successful experiment (Zalizovski et al., 2009) was conducted on 26-30th October 2002 by using the European Incoherent Scatter (EISCAT) facility located near Troms $\varnothing$,
Norway, with the coordinates $69.35 \mathrm{~N}, 19.14$ E. The heater antenna beam was directed toward the magnetic zenith at $12^{\circ}$ zenith angle. The HF operating frequencies varied from 4.0 to 7.95 $\mathrm{MHz}$, the frequencies were chosen to reflect from the F2 peak. Both $\mathrm{O}$ - and $\mathrm{X}$-modes were used for the heating. The $\mathrm{HF}$ facility radiated power varied from 600 to $900 \mathrm{~kW}$. The ionospheric diagnostic was provided by the EISCAT $929 \mathrm{MHz}$ incoherent scatter radar and ionosonde.

The pump signal was recorded at three spaced receiving sites: at the UAS (Antarctica), at the Radio Astronomy Observatory (RAO, Ukraine), and close to Saint Petersburg (StP), Russia. In addition, the HF radiation of the RWM station of time and frequency service located close to Moscow (Russia) was continuously recorded as a test radiation in Antarctica. The layout of experiment is shown in Figure 2.

The experiments were conducted during the fall when sunrise terminator line crossed simultaneously through the interaction region over Tromso and the most remote receiving site in Antarctica.

We should emphasize the peculiarity of the signals received across all three detection sites. The signal spectrum consists of two components, one narrowband $(<0.5 \mathrm{~Hz})$ around the radiated frequency, and the other one broadband (more than $2 \mathrm{~Hz}$ ) shifted from the radiated frequency by about $2 \mathrm{~Hz}$. It is well-accepted that the narrowband stable signal was formed by the side lobes radiation of the antenna. It propagated along the radio paths by the ordinary hop and multi hops mechanisms. Weak variations of the Doppler shift and amplitude of the narrowband signal were not correlated at different paths. The broadband signal component behaved differently. Variations of the Doppler shift 


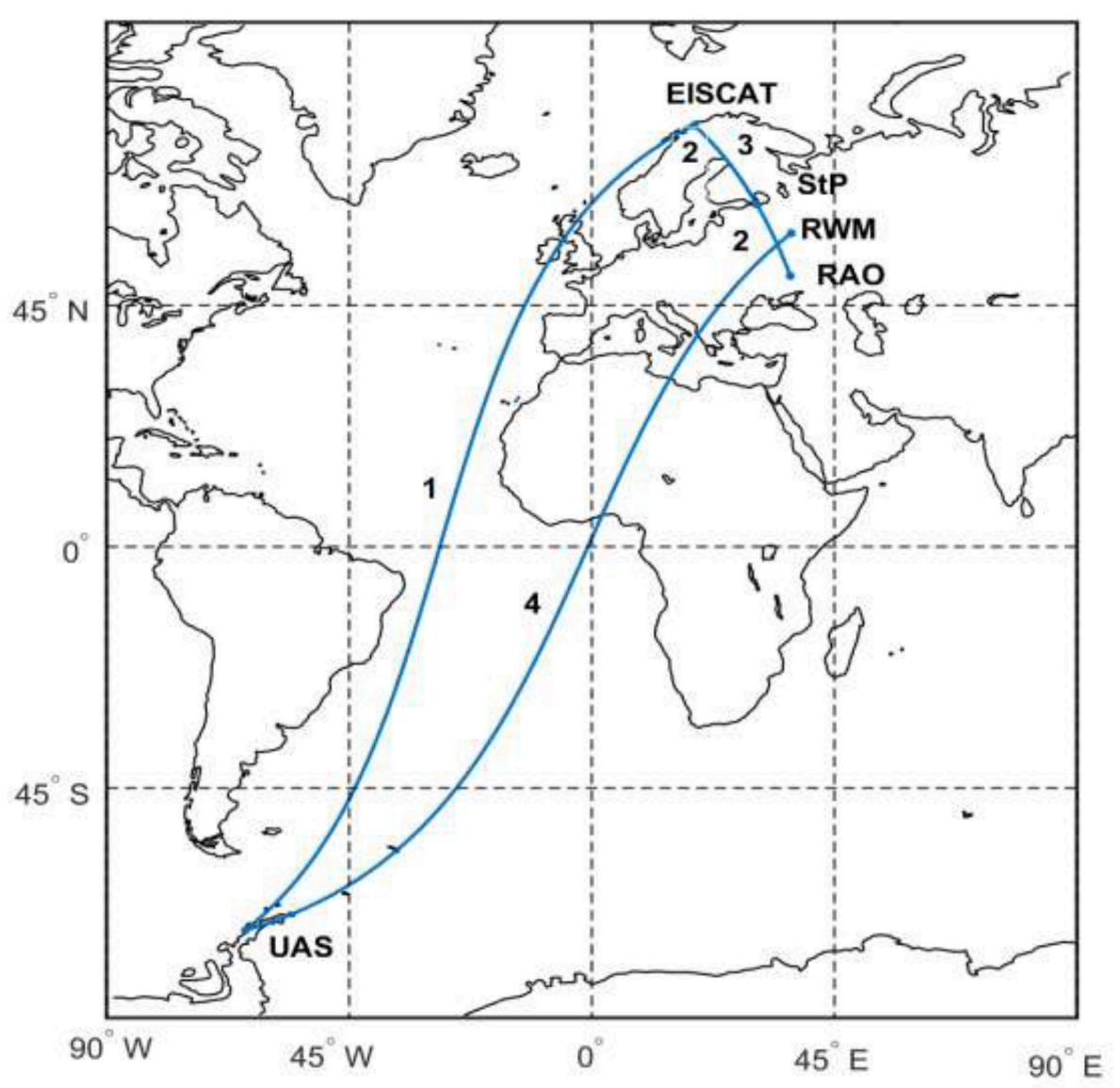

FIGURE 2 | Layout of the experiment. 1: radio path Tromso-UAS (16,300 km); 2: radio path Tromso-RAO (2,400 km); 3: radio path Tromso-StP (1,200 km); 4: radio path RWM-RAO (15,900 km).

and spectral density were well-correlated at all three radio paths. It is illustrated in Figure 3, which shows dynamic spectra of scattered components of the signals received at the UAS (a), RAO (b), and StP (c) on 29th October 2002 from 04:34 to 04:37 UT.

EISCAT heating facility radiated two powerful radio waves O mode, which were shifted from each other by $19 \mathrm{~Hz}$. The facility operated in a $5 \mathrm{~min}$ on, $5 \mathrm{~min}$ off regime. We used two frequencies in order to excite the upper ionosphere plasma oscillations having the combination frequency. The propagation conditions along the radio paths were such that the multiple hop mechanism had not operated. All three panels show wellcorrelated quasiperiodic variations of the Doppler frequency spectra. The correlation coefficient between the pairs of signals detected by the different receivers was higher than 0.7 . Analysis of the geophysical background during the experiment shows that the magnetic field above the HF heating facility experienced similar quasiperiodic variations. Probably they were due to the excitation of the resonance magnetic field micro-pulsations Pc 3. The key question which explains synchronization of the spectra at three different radio paths is how to identify the region which scatters the signals. It is obvious that such region is located in the perturbed area of the ionosphere above the HF heater.
Accordingly, the observed effect was called self-scattering (SS) of the powerful radio wave by the artificial ionospheric turbulence (AIT) (Zalizovski et al., 2009). In the example shown in Figure 3 quasi-periodic variations of the spectral characteristics of the SS signals were due to propagation of the MHD wave through the scattering region thus causing the AIT modulations. The detected effect of self-scattering was also observed during experiments using Sura heater (Kagan et al., 2006). At the Sura SS was studied using the heating frequency close to the fourth electron gyroharmonic. The HAARP campaign conducted from February 21st to March 3rd, 2008 was very successful by using the opportunities given by the upgraded HAARP facility. In fact, one of the transmitters generated the probe signal having a higher frequency than the ionosphere heating frequency. The probe signal was radiated continuously regardless of the heater operation. The receiving sites were in Antarctica, Alaska, Svalbard island (Norway), Greenland, Ukraine and New England (USA). In some cases, digisondes DPS-4 (Reinisch et al., 2006) were used as receivers. A continuously operated probe transmitter allowed us to estimate the relaxation time of the signal scattering irregularities after the HF heater was switched off (Galushko et al., 2008). 

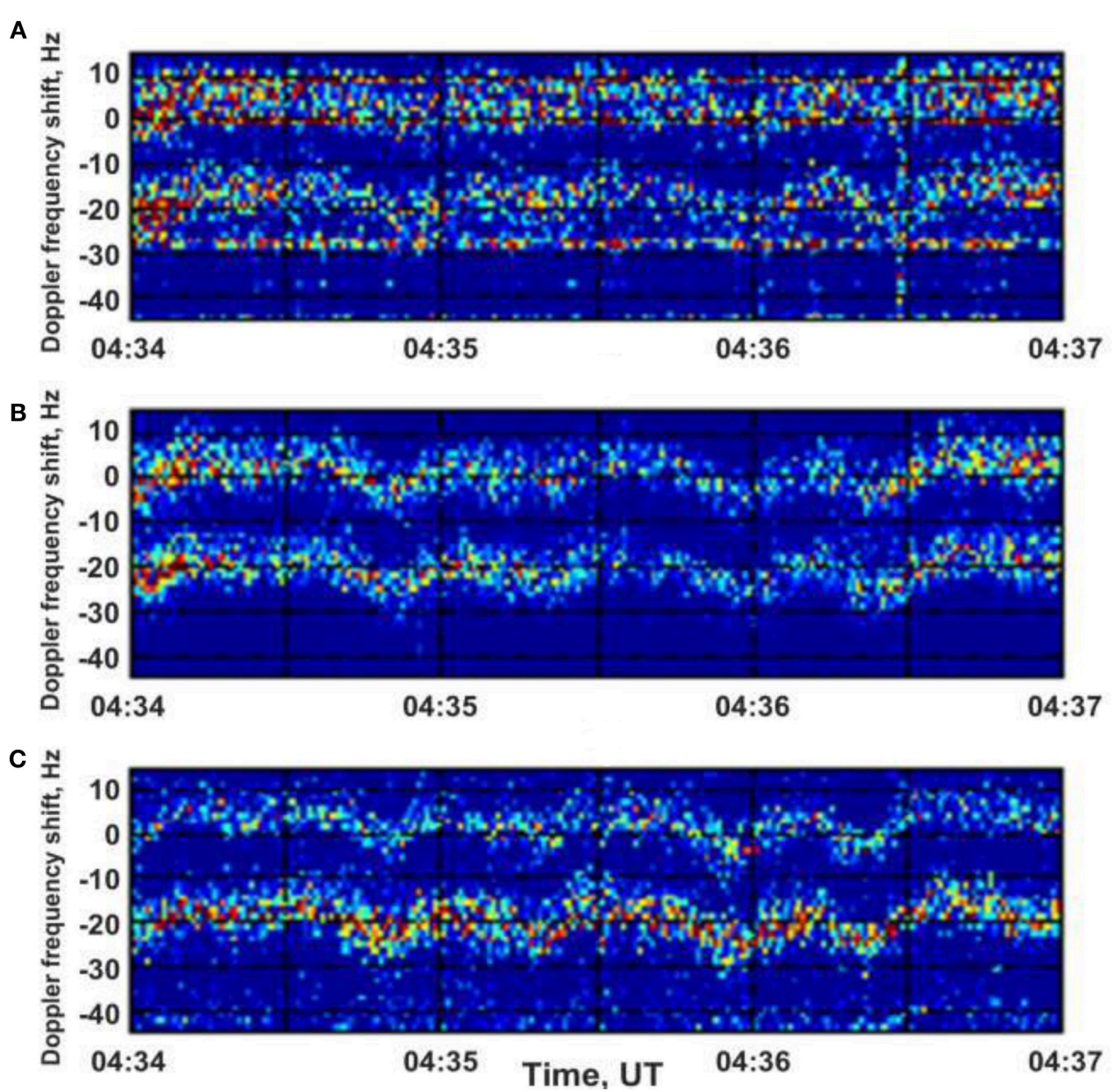

FIGURE 3 | Dynamic spectra for the scattered components of the signal received at the UAS (A), RAO (B), and StP (C) on 29 October 2002 from 04:34 to 04:37 UT.

\section{IONOSPHERIC WAVE GUIDE EXCITATION DETECTED AT HAARP}

A successful experiment designated to excite the ionospheric waveguide was conducted over the super-long HAARP-UAS radio path in June 2014. When developing the layout of the experiment, we considered the existing potentialities to control the spatial AIT spectrum. The HAARP heater used O-mode polarization with the $\mathrm{HF}$ beam directed at $16^{\circ}$ zenith angle and $210^{\circ}$ azimuth angle. As described by Najmi et al. (2015) the chosen HF frequency was close to the 4-th electron gyroharmonic (5.6 MHz). It was gradually increased from 5.67 to $5.94 \mathrm{MHz}$ in $30 \mathrm{kHz}$ increments. The heating at each frequency was made by a long pulse of $100 \mathrm{~s}$ duration. The pulse consisted of 10 sub-pulses of $10 \mathrm{~s}$ each. The ERP was stepped up from 0.7 to $2.5 \mathrm{GW}$ in $0.2 \mathrm{GW}$ increments at each sub-pulse. The artificial ionospheric turbulence excited by the HF beam was probed by the SEE detector located $15 \mathrm{~km}$ away from the HAARP site, which was operated by the Naval Research laboratory; and by the HF Kodiak coherent radar located $670 \mathrm{~km}$ South West from HAARP. AIT scatters the waves emitted by HAARP into the ionospheric waveguide. This waveguide is formed between the electron density peaks of the E- and F-regions. The waveguide is located at high altitude where the electron collision frequency drops and thus the wave attenuation becomes low. This allows the radio waves to propagate to super long distances. During the experiment, starting at about 03 UT, i.e., around 7 p.m. local time, the waveguide was oriented along the Earth's terminator. These radio waves were observed on the ground at the UAS $15,600 \mathrm{~km}$ away from HAARP. The details of the receiver and of the data acquisition system are presented in Najmi et al. (2015).

The main information regarding the AIT development has been provided by monitoring the SEE. The SEE signals are driven by the non-linear interaction of the injected HF wave with the ionospheric plasma that results in broadband emissions at frequencies different from the injected HF frequencies (Thide et al., 2005). They are usually upshifted or/and downshifted from the heater frequency within a range of $100 \mathrm{kHz}$. It is known that the BUM is associated with the pumping of $10 \mathrm{~cm}$ super small striations (SSS) while the DM is associated with the $7-30 \mathrm{~m}$ size striations (Norin et al., 2008). It is illustrated in Figure 4, which shows the power spectral densities (PSD) of broadband 


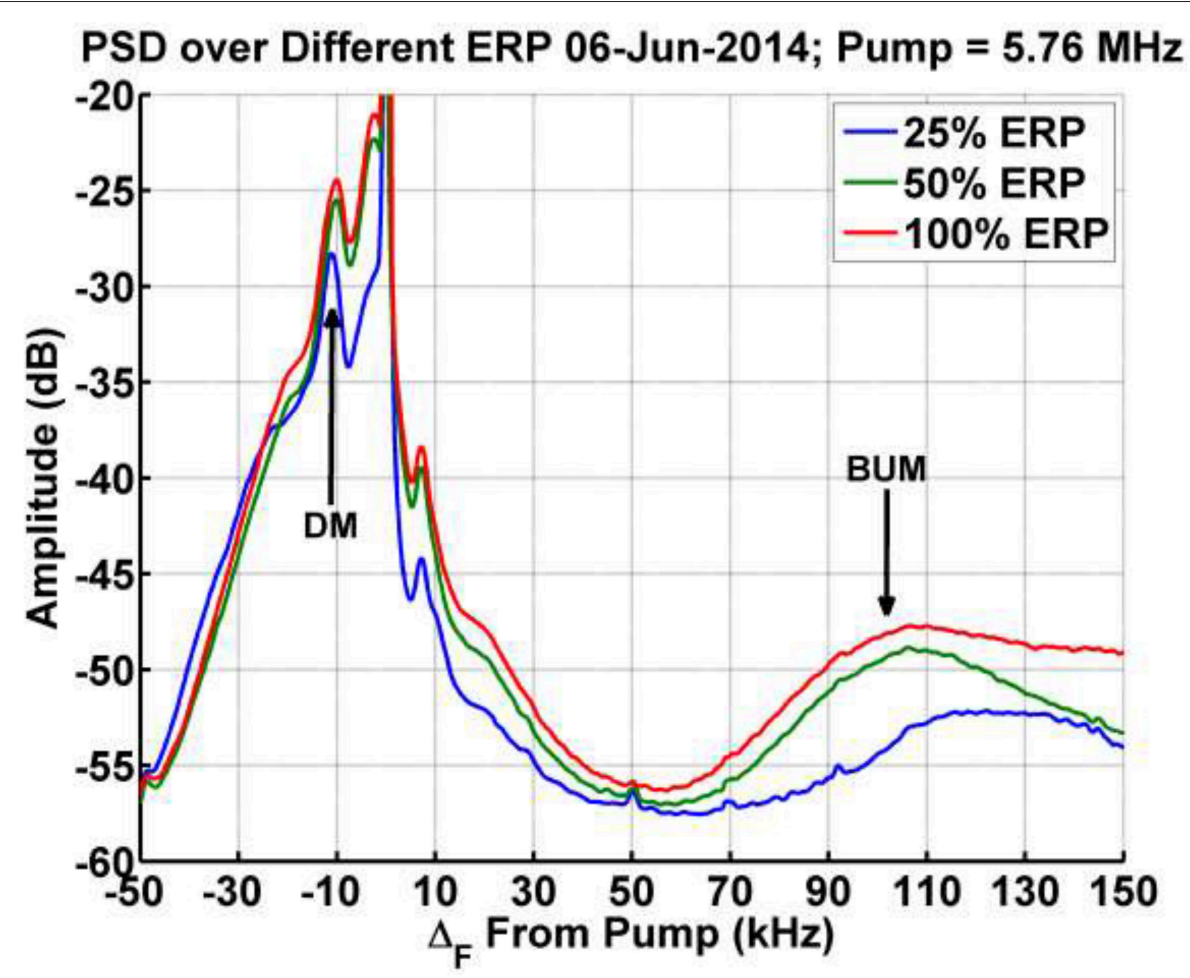

FIGURE 4 | Power spectral densities (PSD) of broadband SEE vs. $\Delta_{\mathrm{F}}$. The traces are averaged over $10 \mathrm{~s}$ of the heating time. Variations of the effective radiated power (ERP) are shown in the figure by the color traces. The heating frequency is shown by the highest peak at $\Delta_{\mathrm{F}}=0$, while the down shifted maximum (DM) and the broad upshifted maximum (BUM) are on the left and right side, respectively [adapted from (Najmi et al., 2015)].

SEE vs. $\Delta_{\mathrm{F}}$. The traces are averaged over $10 \mathrm{~s}$ of the heating time. Variations of the effective radiated power (ERP) are revealed in the figure by the color traces. The heating frequency is shown at the highest peak at $\Delta_{\mathrm{F}}=0$, while the down shifted maximum (DM) and the broad upshifted maximum (BUM) are on the left and right side, respectively.

The development and dynamics of the decimeter AIT irregularities were monitored by the HF Kodiak SUPERDARN coherent radar. The waves radiated by the Kodiak radar have half wavelength $\sim 10 \mathrm{~m}$. They are effectively reflected by the artificial striations in the decimeter range. Thus, the radar detected strong scattering due to the ionospheric heating. This is consistent with the velocity of plasma irregularities calculated by the Doppler broadening at UAS, $\Delta \mathrm{f}_{\mathrm{D}}=1.15-1.40 \mathrm{~Hz}$. It results in velocity of irregularities $v=\frac{c \Delta f_{D}}{2 f_{h}}=30-35 \frac{\mathrm{m}}{\mathrm{s}}$.

The HAARP HF signals were monitored at the UAS Academik Vernadsky. Figure 5 shows the time series of the received power at UAS on June 6th, 2014. Here the heating frequencies are given in $\mathrm{MHz}$. The intensity of the received HF signals vs. elapsed time (i.e., the varying heating frequency) are shown by the color traces. The 8 th $\left(\mathrm{f}_{\mathrm{h}}=5.85 \mathrm{MHz}\right)$ and 9 th $\left(\mathrm{f}_{\mathrm{h}}=5.91 \mathrm{MHz}\right)$ heating cycles are not shown due to their contamination by interference signals. The blue trace shows the measured data while the red trace is the $10 \mathrm{~s}$ moving average. The intensity of detected signal strongly depends on the heating frequency $f_{h}$. For $f_{h}$ slightly above the 4 th gyro-frequency, the intensity of the detected signal was low. The intensity of the detected signal increased with $f_{h}$ and peaked at 5.79 MHz. We tried without any success to measure scattered HF HAARP signals by ground base detectors in Ukraine and Scandinavia, which emphasizes an important role played by Earth's terminator in the waveguide propagation.

Note that the maximum intensity of the signal received at UAS coincides with the $\mathrm{HF}$ heating regime that produces maximum DM SEE. Figure 6 shows amplitudes of SEE DM and SEE BUM, and the intensity of the HF signals received at UAS vs. the pump frequency. The amplitudes are given in $\mathrm{dB}$ normalized by the peak values. In addition, the error bars show the standard deviation of the mean of SNR measured at UAS. The figure reveals that the intensity of the signal detected at UAS is determined by the pump frequency $f_{h}$. In fact, when the BUM is the strongest feature in the SEE spectrum, the HF signal at UAS is suppressed. On the other side, when the DM is the strongest feature in the SEE spectrum, the HF signal increases with $f_{h}$ and peaks at $f_{h}=5.79 \mathrm{MHz}$. It implies that SEE DM and the amplitude of HF signal detected at UAS peak at the same pump frequency.

We need to emphasize that small scale striations $(\sim 10 \mathrm{~cm})$, where excitation is associated with SEE BUM, are inefficient scatters of HF waves, which have the half wavelength of about $25 \mathrm{~m}$. At the same time SEE DM shows excitation of the decameter scale striations which efficiently scatter HAARP's HF radiation into the ionospheric waveguide. This radiation is later detected on the ground at UAS. 


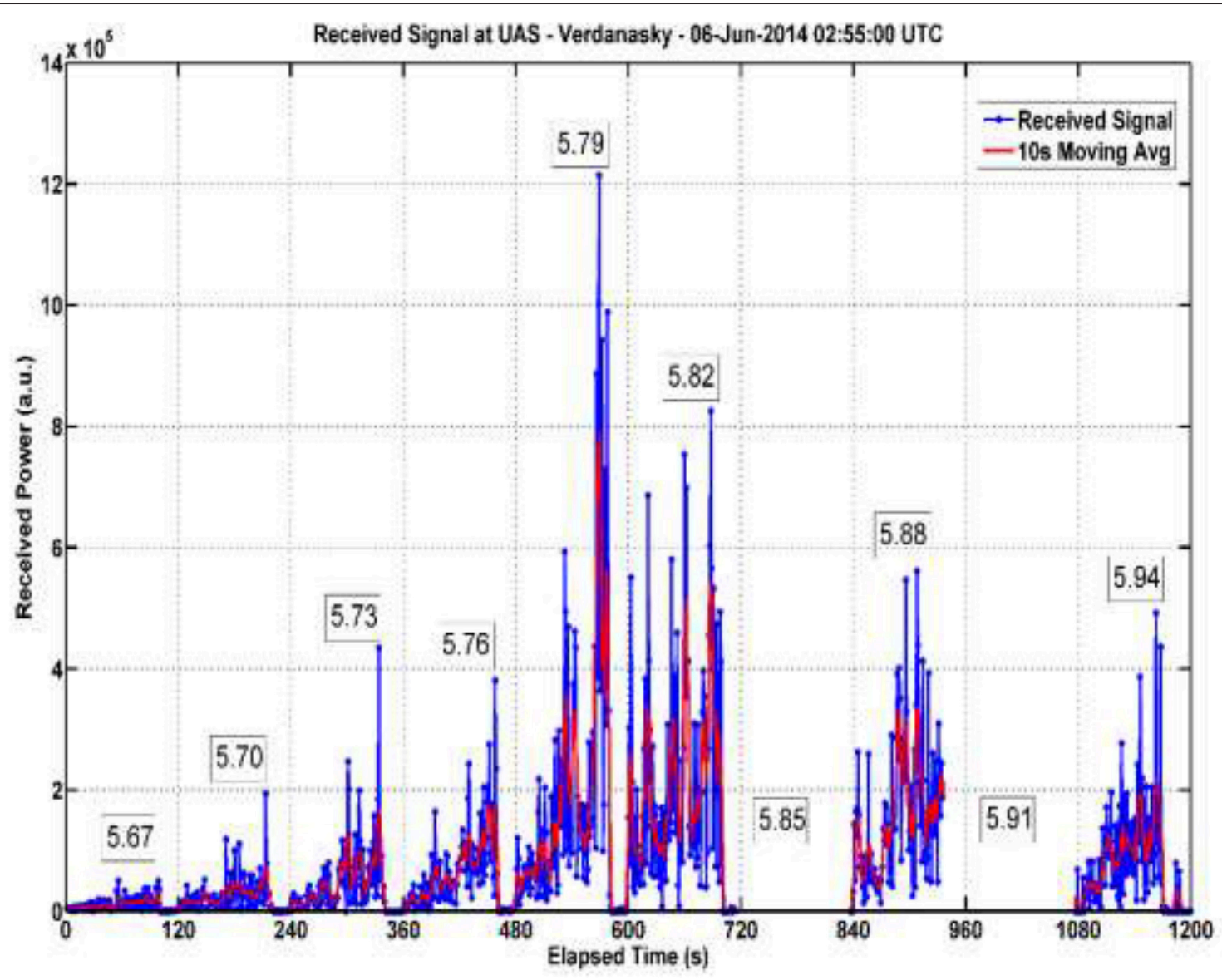

FIGURE 5 | Time series of the received power at UAS on 06/06/2014. Here the heating frequencies are given in MHz. The intensity of the received HF signals vs. elapsed time (i.e., the varying heating frequency) are shown by the color traces [adapted from (Najmi et al., 2015)].

\section{WHISPERING GALLERY EXCITATION DETECTED AT ARECIBO}

It is well-accepted that HF heating of the ionosphere generates the FAI. Resonance scattering of the radio waves on FAI is aspect sensitive, and its indicatrix is oriented in the "mirror" direction.

We consider the Arecibo facility as an example. Since the inclination of the geomagnetic field at Arecibo is about 43 degrees and the powerful HF beam is vertical, the aspect scattered wave will be oriented almost horizontally toward the South (see Figure 7). Such geometry provides a unique opportunity to channel the radio wave energy into the ionospheric waveguide and excites the whispering gallery modes. Note that in the HAARP-UAS experiment (Najmi et al., 2015) the geomagnetic field geometry has not allowed the generation of whispering gallery modes.

To monitor very-long-distance propagation of the HF signals radiated by the Arecibo facility, we used the receiving facilities at the Academik Vernadsky station. The respective signal processing enables us to restore Doppler spectra, angles of arrival, time delays and intensities of the signals. This set of parameters allows us to select different propagation modes of the HF signals.
Figure 8 reveals the geometry of the signal propagation on Arecibo-UAS, Arecibo-LFO, and CHU-UAS.

Transmission in the $\mathrm{CW}$ mode from the $\mathrm{HF}$ time service station CHU (Ottawa, Canada) was used as a reference probe signal for long range propagation (distance between Ottawa and UAS is $\sim 12,300 \mathrm{~km}$ ) which allows us to monitor propagation conditions along the meridional direction for daily and seasonal cycles.

The benefits of the Arecibo geometry were mentioned earlier (the aspect scattering wave is horizontal and directed toward South). A shortcoming of the Arecibo experiment is its moderate ERP. The HF facility radiates $600 \mathrm{~kW}$ power and has an antenna gain of $G=22 \mathrm{~dB}$ at $f=5.1 \mathrm{MHz}$ thus its ERP is 95 MW. Besides, unlike HAARP, which allows to serf the heating frequency in order to bring it close to proper multiple gyro resonance, which pumps up AIT efficiently, Arecibo operates at two fixed frequencies of 5.1 and $8.175 \mathrm{MHz}$. Both are far from the multiple gyro resonances. Thus, to describe very-longdistance propagation at the Arecibo experiment, a detailed signal processing is needed.

The experiment took place near the equinox condition on March 17th, 2018 between 22:00 and 24:00 UT (8-10 pm LT). The 


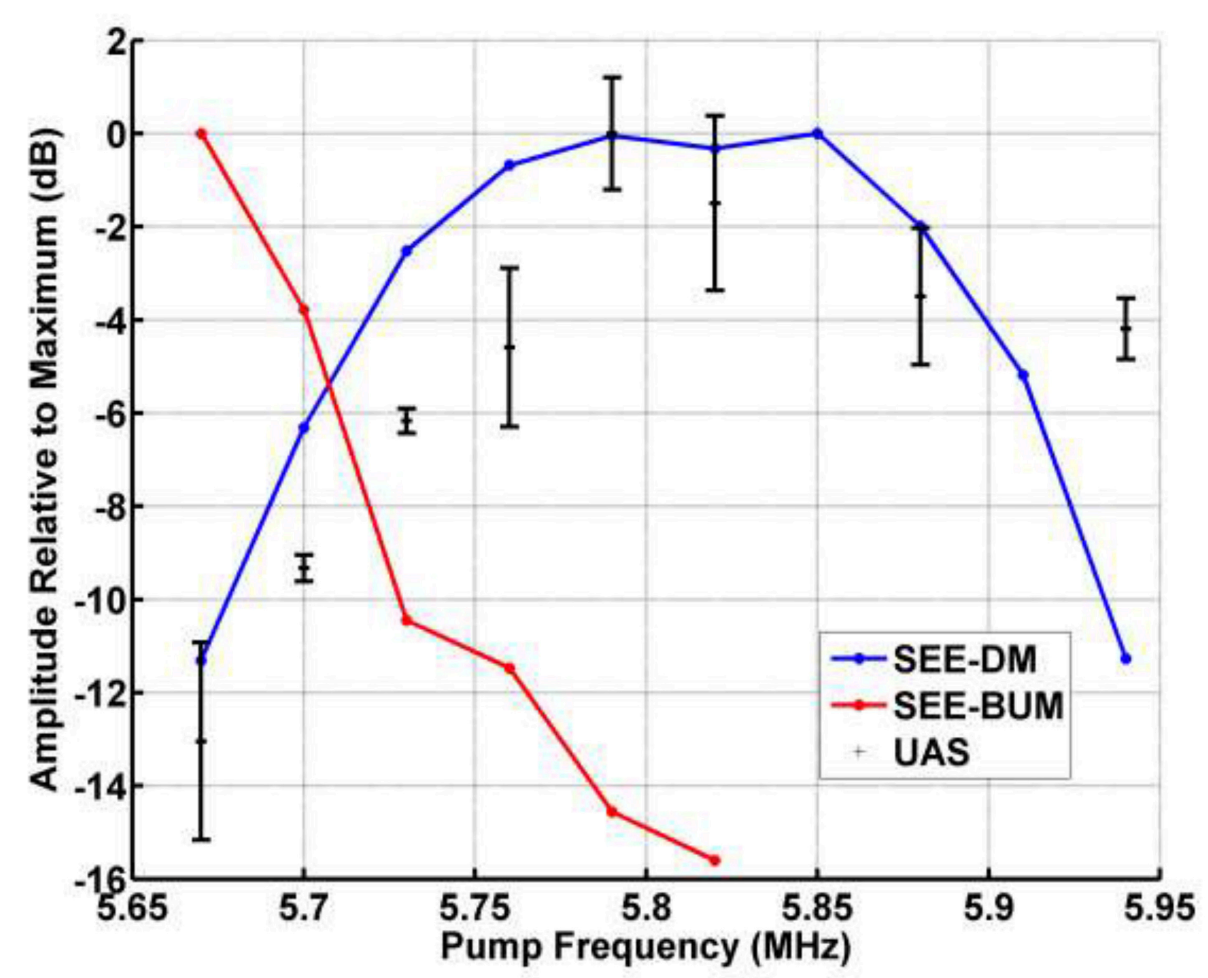

FIGURE 6 | Amplitudes of DM, BUM, and the intensity of the HF signals received at UAS (points with bars) vs. the pump frequency. The amplitudes are given in dB normalized by the peak values. All data points are time averages. Error bars of the HF signals trace are the standard deviation of the mean of SNR measured at UAS [adapted from (Najmi et al., 2015)].

local time at UAS is $1 \mathrm{~h}$ forward. The powerful Arecibo HF facility radiated monochromatic signal with the frequency $5,100,067 \mathrm{~Hz}$, $\mathrm{O}$-mode, provided $\mathrm{F}$ region heating. We used $20 \mathrm{~min}$ heating cycles. During these cycles, for the first 2 min we used $-3 \mathrm{~dB}$ of the ERP, for the next 2 min we stepped up to $-1 \mathrm{~dB}$, for the next 4 min we stepped up to the max ERP $(0 \mathrm{~dB})$, while during the next 2 min we stepped down to $-3 \mathrm{~dB}$, and at the next 2 min we stepped up to $-1 \mathrm{~dB}$, at the next 4 min we stepped up to $0 \mathrm{~dB}$, and finally during the last 4 min of the cycle we stepped down to -10 $\mathrm{dB}$. High frequency stability of the transmitter's generator allows us to conduct coherent spectral processing of the received signals, to select natural as well as artificial ionospheric effects. The frequency of sampling rate was $2 \mathrm{kHz}$. The main characteristic of the received emission was the amplitude spectra, recovered from $10 \mathrm{~s}$ time intervals. The signal intensity was estimated as integral of the square of spectral components in the band +10 to $-15 \mathrm{~Hz}$ with reference to the central frequency $+0.55 \mathrm{~Hz}$ for every $10 \mathrm{~s}$ spectrum. Boundaries for the "effective" band were experimentally detected, and outside of these boundaries the spectral density of the ambient noise does not depend on power of the ionosphere heating wave. The carrying frequency $5,100,067 \mathrm{~Hz}$ was electronically shifted by $+0.55 \mathrm{~Hz}$. Figure 9 shows the spectrogram of the Arecibo signal received at UAS.

Here the narrow band of the signal spectrum corresponds to the carrying frequency. Detailed spectral analysis revealed that the narrow band component practically does not fluctuates with the frequency. Most probably, it forms by the radiation of the
Arecibo antenna side lobes and it propagates along the great circle on Arecibo-UAS route due to the multiple hop mechanism. On the dynamic spectrum on Figure 9, the carrying frequency is marked by the continuous blue line. The main signal power ( $\sim 97 \%)$ is concentrated in the spectral band from -5.45 to $+2.05 \mathrm{~Hz}$, marked by the broken lines. Most probably this part of the spectrum is not related to non-linear ionospheric effects. Intensity "steps" of this component linearly follow changes in the power of the HF heater. The latter was obtained from the experiment $\log$ files. Slow increase $(\sim 17 \mathrm{~dB})$ in the intensity of this signal component over the time of the experiment from 22:00 to 00:05 UT was caused by the changes in the ionospheric conditions along the Arecibo-UAS route. When the experiment passed from daytime to nighttime the radio wave absorption in the lower ionosphere reduced.

It was assumed that the non-linear effects should be noticeable in the broadband component of the spectrum, since this component is formed due to the aspect scattering of the Arecibo radiation by the stimulated field aligned irregularities (FAI).

Spectral power of this component was obtained by extracting the narrow band component at -5.45 to $+2.05 \mathrm{~Hz}$ band from the full power of the received signal in the -15 to $+10 \mathrm{~Hz}$ band. We used the HF heating by 2-4 min pulses, each having constant power. For each of the pulse we averaged the intensity of the received signal in the whole band -15 to $+10 \mathrm{~Hz}$ and in the "broadband." It was assumed that when the Arecibo ERP drops below $25 \%$ of its peak, the non-linear effects do not appear. Slow 


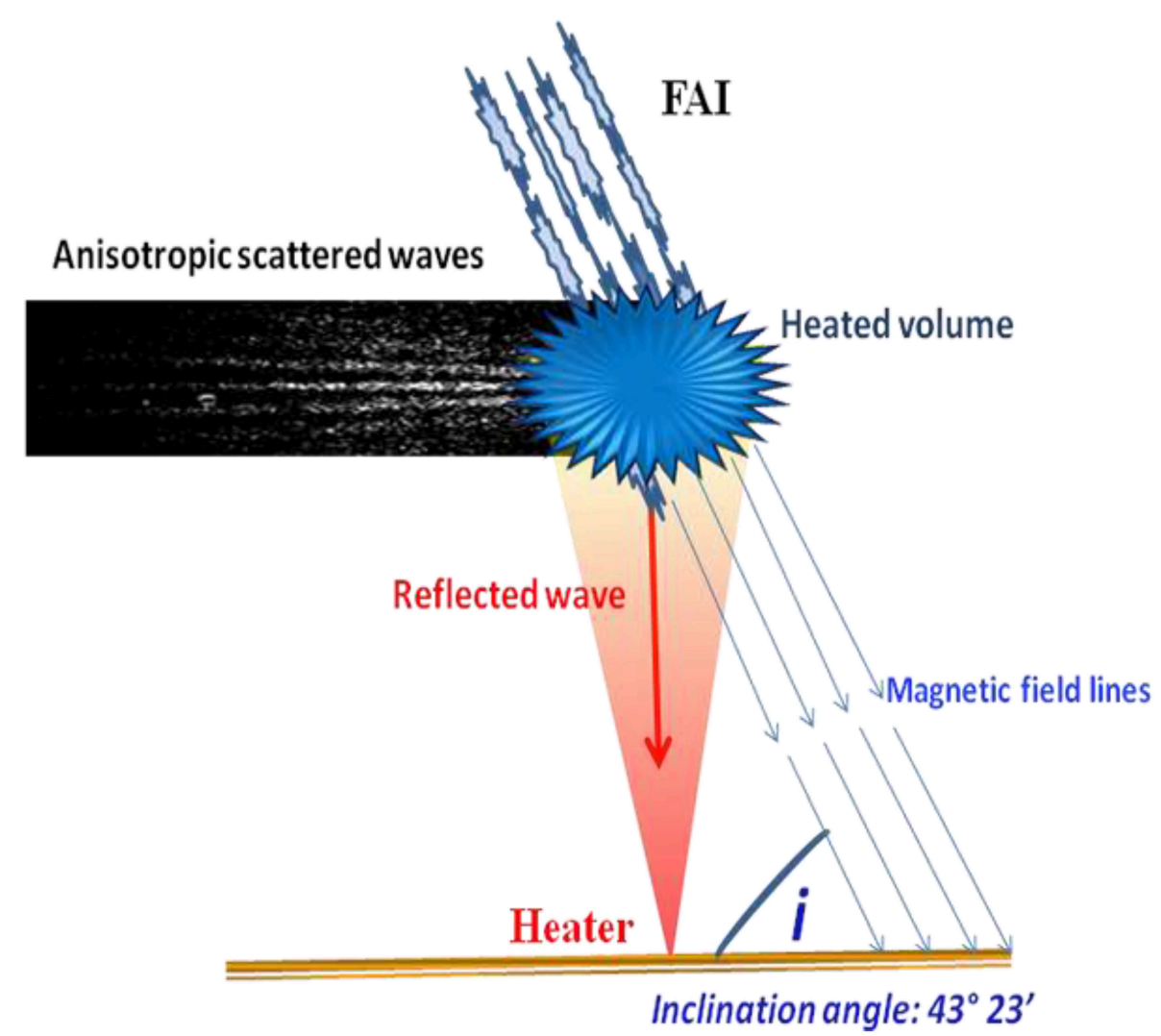

FIGURE 7 | Schematic of the aspect scattering of the radio wave by FAls above Arecibo heater.

changes of the signal received in the whole band, which were estimated at the minimum level of the heater emission, are related to the variations of the propagation conditions in the ionosphere. Based on this relation we derived a trend, which later was used for detrending and normalization of the HF signals.

The main criteria for the search of non-linear effects was the non-proportional increase of the received signals with the power of the Arecibo transmitter. Averaged values of the intensity of the received signal in the whole band show direct proportionality with the power of the Arecibo HF radiation, when the trend had been excluded. Figure 10 shows the time series of the power of Arecibo HF radiation, taken from the log file (red histogram); detrended $10 \mathrm{~s}$ variations of the full intensity (the black traces). Their mean values for corresponding time interval are shown by the black dashed line; the running second-long variations of the SEE intensity (the turquoise curve); their values averaged over $10 \mathrm{~s}$ intervals (the blue curve). Finally, the mean values of the peak SEE power averaged over $1 \mathrm{~min}$ pulses are shown by the magenta curves.

Figure 10 reveals that there is no noticeable correlation between the variations of intensity of the Arecibo signal in the whole spectral band received at UAS and the SEE variations. The mean values of the signal level received in Antarctica (the black dashed lines) nearly exactly mimic the power variations of the Arecibo heater according to the log files of the experiment (the red histogram). A similar analysis applied to the narrowband signals (from -5.45 to $+2.05 \mathrm{~Hz}$ ) shows the same results. It allows one to conclude that the main signal components of the radio beam propagating from Arecibo to UAS are most probably excited by the side lobes radiation of the Arecibo antenna. Notice that cross correlation analyses of the variations of the intensity of the main component of the received signal and variations of DM SEE power do not show any noticeable relation between these processes. The broadband component in Figure 11 behaves differently. First, its intensity does not change proportionally to the log files. Second, under maximum heating power, its intensity variations were well-correlated with the variations of DM SEE power.

Note that the mean intensity steps of the broadband signal are proportional to the heating HF power when the latter is small, although the steps increase non-linearly with ERP when it rises.

Furthermore, we analyzed steps of the SEE intensity under maximum ERP of the Arecibo facility, where we expected that non-linear effects can be developed. Those estimates were checked against the steps of the HF power taken from the log files. There are seven such time intervals during the whole experiment. For four of them the SEE signal steps are by $0.5-2 \mathrm{~dB}$ higher than those of the heating power steps. For remaining three cases the SEE signal steps were smaller than the heating power steps. The cross-correlation analysis of the intensities of the broadband and SEE signal revealed the high degree of their resemblance for all four time-intervals $(22: 27-22: 31,22: 39-22: 42,22: 59-23: 02$, 
23:19-23:22) when the steps of the SEE signals exceeded those of the heating power. In these cases, the cross-correlation coefficient of the two processes was higher than 0.7 . For the remaining three cases the cross-correlation coefficient was $<0.4$. Such correlation cannot be accidental. Increase and reduction in the intensity of SEE signals correspond to synchronous changes in the broadband component of the signal received at UAS.

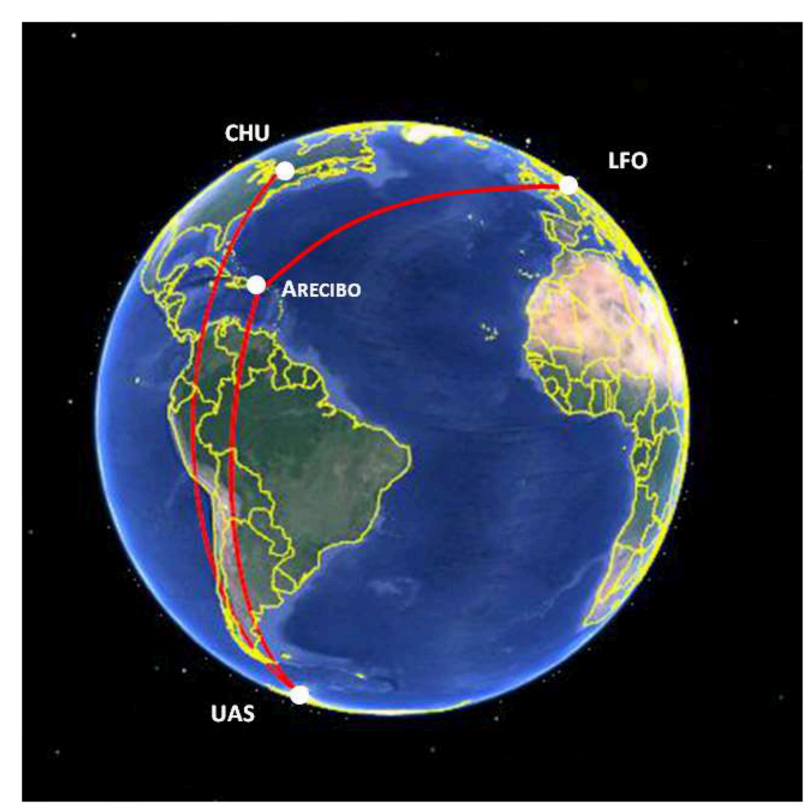

FIGURE 8 | Geometry of the long range radio paths: Arecibo-UAS (9,187 km), as well as CHU (Ottawa, Canada-UAS (12,332 km), and Arecibo-LFO $(9,393 \mathrm{~km})$.
Similar spectral and cross correlation analyses were carried out for the signals received at the two test radio paths AreciboLFO and CHU-UAS. No relation between variations of different signal components with that of DM SEE power was detected. Therefore, we deduced that the steps of the received HF signal do not depend on spectral frequency band and nearly mimic log files steps; there is no sufficient correlation between variations of the Arecibo ERP and SEE peak power.

Therefore, we can state that conditions of the aspect scattering by FAIs were fulfilled only at Arecibo-UAS radio path. A significant increase (by 5-7 dB) of the level of signal received in Antarctica in phase with the growing intensity of DM SEE is likely to confirm the channeling of energy of the aspect scattered radio wave due to whispering gallery mode. The focusing of the signal was detected by UAS in the nighttime when the E region was absent with no valley. The ionospheric conditions at the receiving site in Antarctica were continuously monitored by the UAS ionosonde, while at Arecibo the incoherent scatter radar was used for this purpose.

\section{CONCLUSIONS}

The paper discusses the three experiments conducted over 16 years in which very-long-distance wave propagation was induced by the non-linear effect in the ionosphere irradiated by the powerful HF transmitter.

In the first experiment performed in 2002, the result was serendipitously obtained when using the HF EISCAT facility which radiated monochromatic stationary signals. Three radio paths of different lengths and aligning have detected the broadband spectral components which were strongly intercorrelated. In some case the intensity of these components was either comparable to or higher than the intensity of the narrowband signals formed by the multi-hops of the antenna side lobs emission. The observed effect was caused by self-scattering

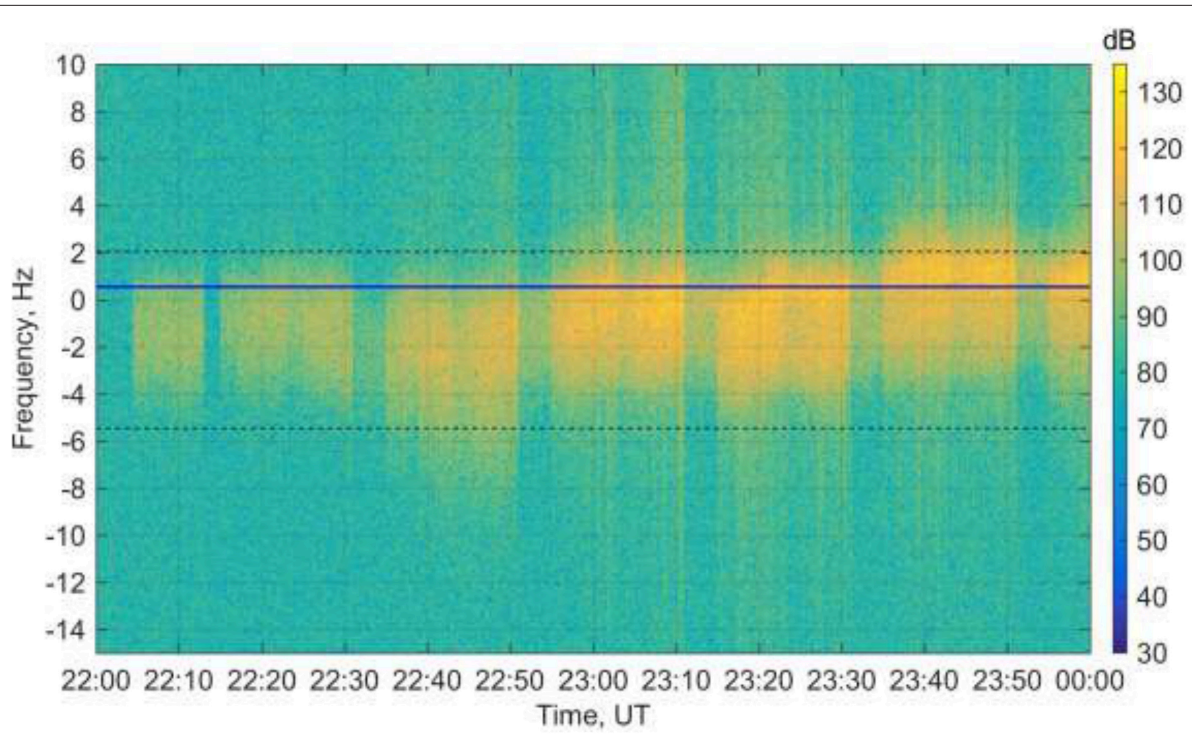

FIGURE 9 | Spectrogram of the Arecibo heater signal received at UAS on March 17, 2018. 


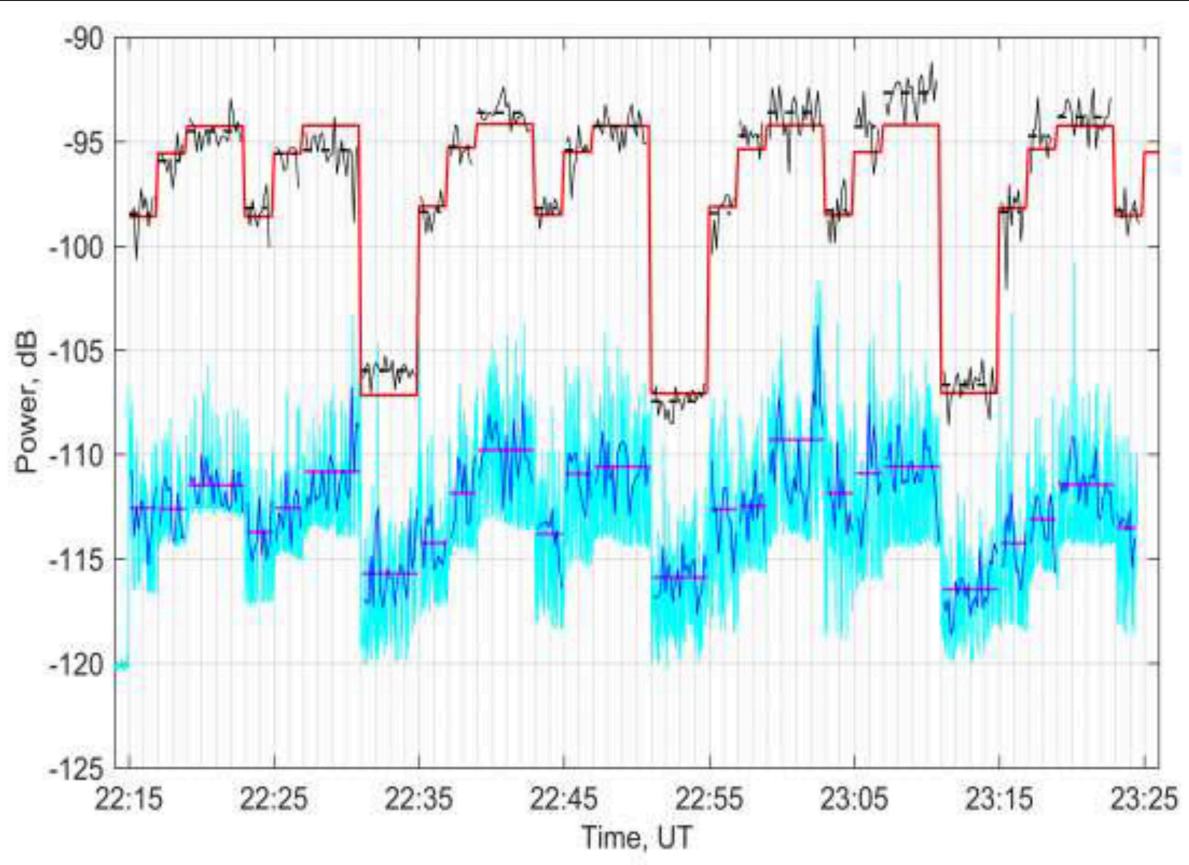

FIGURE 10 | Time series of the Arecibo heater signal received at UAS in the whole spectral band, and the peak intensity of the DM SEE signal received at Arecibo. Red histogram - log file of the heater, black curves - power of received signal at the UAS, black dashed lines an average level of signal power, turquoise curves-intensity of SEE. March 17, 2018.

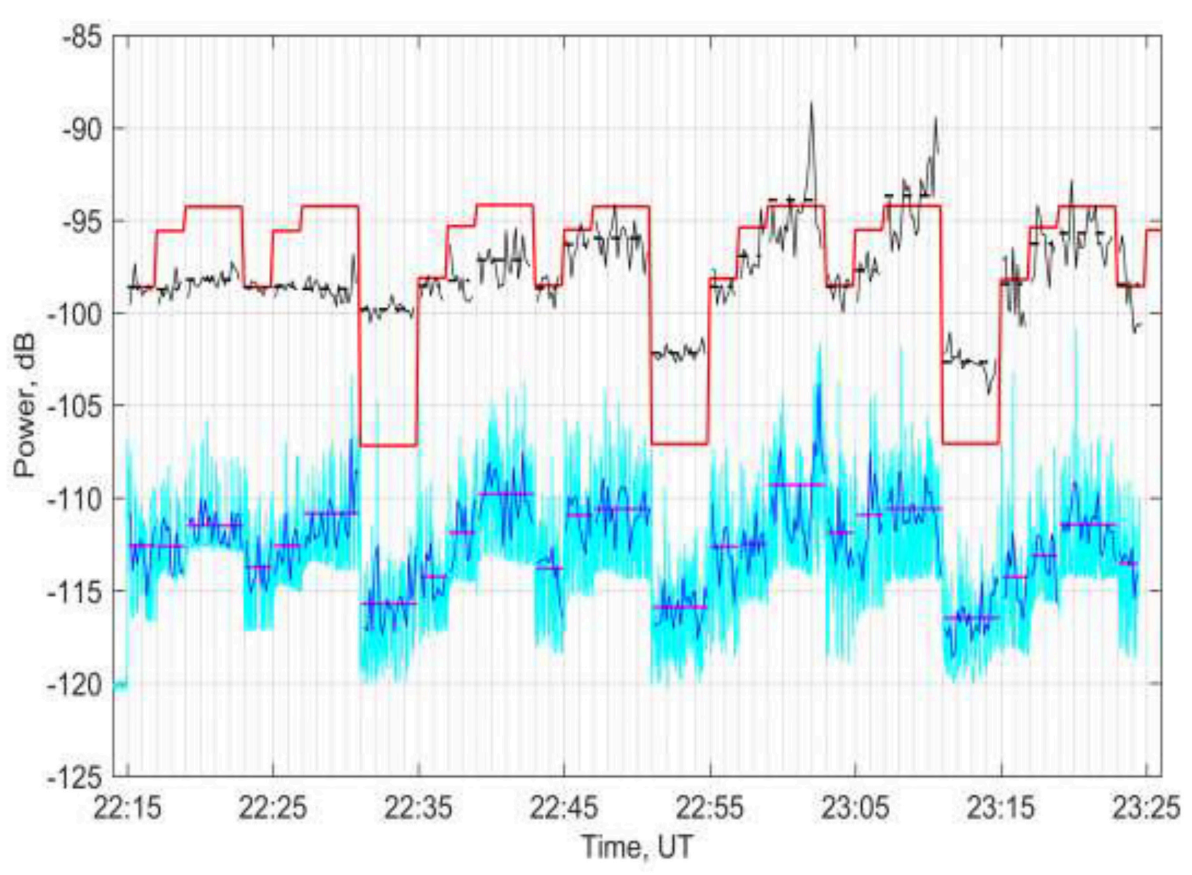

FIGURE 11 | Time series of the intensity of the broadband component of HF signal received at UAS (black curve), noise intensity (the blue curve), red histogram-log file of heater, and turquoise curves-intensity of DM SEE. March 17, 2018.

of the powerful HF emission by the ionospheric irregularities created by the HF emission itself. The broadband spectral component was created by the "secondary" source formed by the scattering of the Artificial Ionospheric Turbulence excited by the ionospheric heating in the region above the HF facility. Temporal and spatial variations of the AIT region due to the natural 
and stimulated drift affect the signal spectra of the scattered component at all the radio links involved. The significant intensity of the self-scattered signal at the very long radio link, which exceeded the intensity of multi-hop narrowband component, allowed us to predict that the ionospheric wave guide can be fed by the secondary source located inside it.

In the second experiment performed in 2014 at the HAARP HF-facility the hypothesis of the artificial feeding of the ionospheric waveguide was proved by using a more sophisticated setup. At the same time, we figured out how to control the AIT efficiency in the domain of meter and decameter scales by sweeping the heating frequency across one of a multiple electron gyroharmonic. Stimulated electromagnetic emission was used to probe the AIT spectrum. During the experiment we detected a sharp increase in the intensity of the HF signal on the very-longdistance radio path HAARP-UAS when the heating frequency approached the 4th electron gyroharmonic.

The third experiment performed in 2018 at the Arecibo facility used the HF energy channeling into the ionospheric waveguide due to the aspect scattering of the radio emission by the field aligned irregularities stretched along the magnetic field lines. The required conditions were fulfilled in the Arecibo heating experiment where the inclination of geomagnetic field is about 43 degrees while the powerful HF beam is vertical, thus the aspect scattered wave will be oriented almost horizontally toward the South. The wave guide was directed toward UAS. Such geometry provides a unique opportunity to channel the radio wave energy into the ionospheric waveguide and excites the whispering gallery modes.

Probing of AIT is obtained from analysis of the radio waves self-scattered into the ionospheric waveguide and then detected at far distance from the heater. However, a probing HF transmitter located in the vicinity of the powerful facility could be very useful for the diagnostic. The frequency of the probing transmitter should be slightly above the heating frequency.

\section{AUTHOR CONTRIBUTIONS}

YY: problem formulation and organization of experiments related to detection of super-long-distance propagation of radio waves generated by HF heaters; GM: organization of the experimental campaigns at HAARP and Arecibo and interpretation of the experimental results; AZ: conducting experiments in Antarctica and making estimates of the radio wave aspect scattering by the natural and artificial irregularities; AK: creating the net of HF receivers at Ukraine, Antarctica, and Arctic operated through the internet and data processing and interpretations; AR: spectral and correlation analysis of the signals propagated along superlong-distances; EN: organizing and conducting experimental campaign at Arecibo; PB: study AIT by using the SEE diagnostic and interpretation of the experimental results; SB: collecting and process SEE data at HAARP and Arecibo; SG: theoretical modeling of generation mechanisms of AIT and SEE and interpretation of the experimental results; AS: processing SEE data at Arecibo; ES: SEE data processing and interpretations.

\section{ACKNOWLEDGMENTS}

All data used to produce figures and results for this paper are available for download via FTP at: http://www.geospace.com. ua/data.html. GM gratefully acknowledges support from the AFOSR Grant No. F9550-14-1-0019. The experimental studies were sponsored by Ukrainian projects Yatagan (N 0116U000035), Spitsbergen (N 0118U000562), and Geliomaks (N 0118U100280). They were also partially supported by Partner Project EOARDSTCU (P 667). The authors are grateful to National Antarctic Scientific Center of Ukraine, and to personnel of the Ukrainian Antarctic Station Academik Vernadsky for their help with the experiments. GM gratefully acknowledges useful discussions with Dennis Papadopoulos, SEE processing for the Arecibo experiment (SG, ES, and AS) was supported by the Russian Science Foundation Grant 14-12-00706. The research at the Naval Research Laboratory was sponsored by the NRL 6.1 Base Program. The Arecibo Observatory is a facility of the National Science Foundation operated under a cooperative agreement by University of Central Florida, Yang Enterprises, and Universidad Metropolitana de Puerto Rico. We thank Mike Sulzer and Nestor Aponte for his assistance with the analysis of the ISR data.

\section{REFERENCES}

Bernhardt, P. A., Selcher, C. A., and Kowtha, S. (2011). Electron and ion Bernstein waves excited in the ionosphere by high power EM waves at the second harmonic of the electron cyclotron frequency. Geophys. Res. Lett. 38:L19107. doi: 10.1029/2011GL049390

Bernhardt, P. A., Selcher, C. A., Lehmberg, R. H., Rodriguez, S., Thomason, J., McCarrick, M., et al. (2009). Determination of the electron temperature in the modified ionosphere over HAARP using HF pumped stimulated Brillouin scatter (SBS) emission lines. Ann. Geophys. 27, 4409-4427. doi: 10.5194/angeo-27-4409-2009

Budden, K. G., and Martin, H. G. (1962). The ionosphere as a whispering gallery. Proc. R. Soc. Lond. A 265, 554-569. doi: 10.1098/rspa.1962.0042

Carozzi, T. D., Thide, B., Grach, S. M., Leyser, T. B., Holz, M., Komrakov, G. P., et al. (2002). Stimulated electromagnetic emissions during pump frequency

sweep through fourth electron cyclotron harmonic. J. Geophys. Res. 107:1253. doi: 10.1029/2001JA005082

Davies, K. (1989). Ionospheric Radio. London: P. Peregrinus on behalf of the Institution of Electrical Engineers.

Erukhinov, L. M., Matyugin, S. N., and Uryadov, V. P. (1975). Radio-wave propagation in an ionospheric wave channel. Radiophys. Quant. Elec. 18, 958-963. doi: 10.1007/BF01038191

Galushko, V. G., Koloskov, A. V., Paznukhov, V. V., Reinisch, B. W., Sales, G. S., Yampolski, Y. M., et al. (2008). Self-Scattering of the HF heater emissions observed at geographically dispersed receiving sites. IEEE Antennas Propagat. Mag. 50, 155-161. doi: 10.1109/MAP.2008.4768950

Grach, S. M., Sergeev, E. N., Mishin, E. V., and Shindin, A. V. (2016). Dynamic properties of ionospheric plasma turbulence driven by high-power high-frequency radiowaves. Phys. Usp. 59, 1091-1128. doi: 10.3367/UFNe.2016.07.037868 
Gurevich, A. V. (2007). Nonlinear effects in the ionosphere. Phys. Usp. 50, 1091-1121. doi: 10.1070/PU2007v050n11ABEH006212

Kagan, L. M., Nicolls, M. J., Kelley, M. C., Frolov, V. L., Belikovich, V. V., Bakhmet'eva, N. V., et al. (2006). Optical and radio frequency diagnostics of the ionosphere over the sura facility: review of results. Radio Phys. Radio Astronomy $11,221-241$.

Leyser, T. B., Thidé, B., Derblom, H., Hedberg, A., Lundborg, B., Stubbe, P., et al. (1989). Stimulated electromagnetic emission near electron cyclotron harmonics in the ionosphere. Phys. Rev. Lett. 63:11. doi: 10.1103/PhysRevLett.63.1145

Leyser, T. B., Thide, B., Waldenvik, M., Goodman, S., Frolov, V. L., Grach, S. M., et al. (1993). Spectral structure of stimulated electromagnetic emissions between electron cyclotron harmonics. J. Geophys. Res. 98, 17595-17606. doi: 10.1029/93JA01387

Leyser, T. B., Thide, B., Waldenvik, M., Veszelei, E., Frolov, V. L., Grach, S. M., et al. (1994). Downshifted maximum features in stimulated electromagnetic emission spectra. J. Geophys. Res. 99, 19555-19568. doi: 10.1029/ 94JA01399

Najmi, A., Milikh, G., Yampolski, Y. M., Koloskov, A. V., Sopin, A. A., Zalizovski, A., et al. (2015). Studies of the ionospheric turbulence excited by the fourth gyroharmonic at HAARP. J. Geophys. Res. 120, 6646-6660. doi: 10.1002/2015JA021341

Norin, L., Grach, S. M., Leyser, T. B., Thide, B., Sergeev, E. N., and Berlin, M. (2008). Ionospheric plasma density irregularities measured by stimulated electromagnetic emission. J. Geophys. Res. 113:A09314. doi: 10.1029/2008JA013338

Norin, L., Leyser, T. B., Nordblad, E., and Thide, B. (2009). Unprecedentedly strong and narrow electromagnetic emissions stimulated by HF radio waves in the ionosphere. Phys. Rev. Lett. 102:065003. doi: 10.1103/PhysRevLett.102. 065003

Ponomarenko, P. V., Leyser, T. B., and Thidé, B. (1999). New electron gyroharmonic effects in HF scatter from pump-excited magnetic fieldaligned ionospheric irregularities. J. Geophys. Res. 104, 10081-10087. doi: 10.1029/1999JA900039
Reinisch, B. W., Galkin, I. A., Khmyrov, G., Kozlov, A., and Kitrosser, D. F. (2006). Automated collection and dissemination of ionospheric data from the digisonde network. Adv Radio Sci. 2, 241-247. doi: 10.5194/ars-2-241-2004

Sergeev, E., Grach, S., Shindin, A., Mishin, E., Bernhardt, P., Briczinski, S., et al. (2013). Artificial ionospheric layers during pump frequency stepping near the 4th gyroharmonic at HAARP. Phys. Rev. Lett. 110:065002. doi: 10.1103/PhysRevLett.110.065002

Thide, B., Sergeev, E. N., Grach, S. M., Leyser, T. B., and Carozzi, T. D. (2005). Competition between Langmuir and upper hybrid turbulence in an HF pumped ionosphere. Phys. Rev. Lett. 95:25. doi: 10.1103/PhysRevLett.95.255002

Thorne, G. D., and Blood, D. W. (1974). First observations of RF backscattering from field-aligned irregularities produced by ionospheric heating. Rad. Sci. 9, 917-921. doi: 10.1029/RS009i011p00917

Yampolski, Y. M., Beley, V. S., Kascheev, S. B., Koloskov, A. V., Somov, V. G., Hysel, D. L., et al. (1997). Bistatic HF radar diagnostics induced field-aligned irregularities. J. Geophys. Res. 102, 7461-7467. doi: 10.1029/97JA00037

Zalizovski, A. V., Kashcheyev, S. B., Yampolski, Y. M., Galushko, V. G., Belyey, V. S., Isham, B., et al. (2009). Self-scattering of a powerful HF radio wave on stimulated ionospheric turbulence. Radio Sci. 44, 241-253. doi: 10.1029/2008RS004111

Conflict of Interest Statement: The authors declare that the research was conducted in the absence of any commercial or financial relationships that could be construed as a potential conflict of interest.

Copyright (c) 2019 Yampolski, Milikh, Zalizovski, Koloskov, Reznichenko, Nossa, Bernhardt, Briczinski, Grach, Shindin and Sergeev. This is an open-access article distributed under the terms of the Creative Commons Attribution License (CC BY). The use, distribution or reproduction in other forums is permitted, provided the original author(s) and the copyright owner(s) are credited and that the original publication in this journal is cited, in accordance with accepted academic practice. No use, distribution or reproduction is permitted which does not comply with these terms. 